\section{CPS-164 ORAL KETAMINE IN UNMANAGEABLE CHRONIC PAIN: A CASE REPORT}

I Martínez Aguirre, U Blazquez Urtizberea*, MM Alvarez Lavin, M Alonso Diez, JA Dominguez Menendez, A Llona Armada, A Aguirrezabal Arredondo. OSI Bilbao Basurto, Hospital Pharmacy, Bilbao, Spain

10.1136/ejhpharm-2019-eahpconf.313

Background The neuropathic pain management which is refractory to opioids treatments demands the development of new analgesics or new ways of using our classic medicines. Ketamine is scarcely used as an anaesthetic, but with an increase in indication as an analgesic. However, no oral formulation is commercialised in our country.

Purpose To develop an oral formulation of ketamine and assess its efficacy in refractory neuropathic pain.

Material and methods A clinical record review of a 43-yearold male was carried out. After an accident in 2006, he experienced unapproachable neuropathic pain and he had a history of two admissions due to autolytic ideation motivated by poor pain control. From 2008 to 2015 he had been in treatment with various opiods and other non-opioid analgesics and antiinflamatory drugs, without pain control or improvement despite high doses. A ketamine oral solution was developed at the pharmacy according to Good Manufacturing Practice: $20 \mathrm{ml}$ of Ketolar $50 \mathrm{mg} / \mathrm{ml}$ ampoule and syrup quantity sufficient for $100 \mathrm{ml}$, obtaining $10 \mathrm{mg} / \mathrm{ml}$ of oral solution.

Results In September 2016, the patient started with intravenous ketamine at a dose of $0.2 \mathrm{mg} / \mathrm{kg}$ with prior informed consent. He received three sessions with a $50 \%$ pain relief on the Global Clinical Impression Scale (GGI). On March 2017, the pain reappeared, and sessions were repeated monthly with a good response. In that time, the dose of transdermal fentanyl was reduced. In June 2017, oral ketamine solution $10 \mathrm{mg} / \mathrm{ml}$ was formulated, dosed at $50-70 \mathrm{mg} / 8$ hours. The patient scored 9 for his quality life on the GGI scale. As an adverse reaction, a slight and transient dizziness was observed. In August 2017, he continued with a descending pattern of opioids to discontinue. Currently, the patient continues with oral ketamine dosed at $50 \mathrm{mg} / 8$ hours and fentanyl on demand, and the pain is well controlled.

Conclusion The ketamine solution formulated has contributed to the control of the neuropathic pain and achieving the therapeutic objectives. Besides, it has reduced the opioids dose of this patient.

\section{REFERENCES AND/OR ACKNOWLEDGEMENTS}

1. Neira Reina F. La ketamina en el tratamiento del dolor crónico según medicina basada en la evidencia. Rev Soc Esp Dolo 2016;23:292-306.

No conflict of interest.

\section{CPS-165 LIDOCAINE 5\% PLASTER: IS IT WORTH THE PAIN?}

M Chouchana*, E Moutel, E Ducret, O Chauvel, F Plassart, JL Pons. Centre Hospitalier Victor Dupouy, Pharmacy, Argenteuil, France

\subsection{6/ejhpharm-2019-eahpconf.314}

Background Lidocaine 5\% plaster is licensed for the symptomatic relief of pain associated with post-herpetic neuralgia. Over the past 4 years, an increase of more than $50 \%$ of its consumption has been observed within our hospital.
Purpose The objective of this work was to evaluate the use of this drug in our institution as well as the impact of hospital practices on primary care.

Material and methods A retrospective study of 5\% lidocaine plaster prescriptions was conducted from 1 January 2017 to 1 May 2018. Using computerised and physical patient records, the following data were collected: age, service, indication, dosage, duration of prescription and mention on the discharge prescription.

In parallel, the evolution of hospital spending on this drug was compared to the evolution of the expenses generated by hospital outpatients' prescriptions.

Results In this evaluation, 111 prescriptions of lidocaine 5\% plaster were analysed for the period studied. The average age of patients was 72 years (18-99 years). Less than half of the prescriptions mentioned the therapeutic window (53/111). The largest prescribing services were the palliative care unit (36/ 111) and the geriatric long-term care unit (28/111). Regarding the indications, only $3 \%(3 / 111)$ of the prescriptions matched the official labelling, $79 \%$ (88/111) were off-label and $18 \%$ (20/111) did not specify an indication. The lidocaine 5\% plaster was mentioned on approximately $50 \%$ of the discharge prescriptions.

Conclusion Most of the prescriptions analysed concern offlabel indications initiated by doctors specialised in pain management. The bibliographic review shows efficacy results that vary from one publication to another. In consequence it is necessary to set up a multidisciplinary working group to supervise the prescription procedures in our hospital (characterisation and evaluation of neuropathic pain, validation of the main indications).

This initiation of this work already shows an impact on primary care: since the introduction of a systematic pharmaceutical control on the dispensing of this drug within the hospital, expenses in community pharmacies were reduced by $16 \%$ ( $€ 232000$ in 2016 versus $€ 195000$ in 2017).

This first evaluation allows us to assess the use in real life of an increasingly prescribed anaesthetic medication.

\section{REFERENCES AND/OR ACKNOWLEDGEMENTS}

https://www.has-sante.fr/portail/upload/docs/application/pdf/ 2012-06/versatis_ct_8107.pdf

No conflict of interest.

\section{CPS-166 IS THERE STILL A PLACE FOR CHLORAL HYDRATE SYRUP IN HOSPITAL?}

O El Hamdaoui*, A Raghani, A Rhars, Y Elalaoui, Y Bensouda. Faculty of Medicine and Pharmacy- Mohammed V University- Rabat- Morocco, Hospital Pharmacy- Specialty Hospital, Rabat, Morocco

\subsection{6/ejhpharm-2019-eahpconf.315}

Background Sedation is frequently essential for successful magnetic resonance imaging (MRI) for infant and child patients. Chloral hydrate syrup (CHS) remains the only product used orally for this purpose in the Specialty Hospital, Ibn Sina University Hospital of Rabat, Morocco.

Purpose This study evaluates the use and economic interest of the CHS administration for sedation in infants and children undergoing MRI in our hospital.

Material and methods Prospective study included 30 infants and children, 8 to 48 months' old (mean, 20.71 \pm 13.42 
months), who were given oral chloral hydrate, $50 \mathrm{mg} / \mathrm{kg}$, for sedation before MRI. The study was limited to children who weighed $25 \mathrm{~kg}$ or less. Sedation was considered successful when MRI studies were completed and at least $95 \%$ of the images had few or no motion artifacts.

Results The overall length of time to achieve sedation ranged from 8 to $30 \mathrm{~min}(13.5 \pm 11.33 \mathrm{~min})$; the overall mean duration of sedation ranged from 10 to $45 \mathrm{~min}(29.5 \pm 5.02 \mathrm{~min})$; and the overall mean length of time to return to normal activity was $30 \mathrm{~min}$ to 3 hour $(47.3 \pm 16.2 \mathrm{~min})$. Other studies reported that chloral hydrate was more effective than midazolam in facilitating the completion of painless imaging studies, although it has a longer onset and duration, and reported minimal adverse events (the only side effect observed was vomiting in $15 \%$ of children). ${ }^{12}$ On the pharmaco-economic side, the hospital preparation of the CHS $5 \%$ in a bottle of $100 \mathrm{ml}$ costs $€ 1.85$. The direct cost to prepare the sedation is $€ 0.37$ for each child of $20 \mathrm{~kg}$ versus $€ 1.24$ for sedation of the child with the same weight by Midazolam.

Conclusion The low adverse events for CHS, and the much lower cost of its use to induce sedation for a short time has made CHS our preference for sedation in infants and children undergoing MRI in our hospital.

\section{REFERENCES AND/OR ACKNOWLEDGEMENTS}

1. Roach CL, Husain N, Zabinsky J, et al. Moderate sedation for echocardiography of preschoolers. Pediatr Cardiol 2010;31:469-73.

2. Hare M. Question 1: chloral hydrate or midazolam: which is better for sedating children for painless diagnostic imaging? Arch Dis Child 2012;97:750-2.

No conflict of interest.

\section{CPS-167 STUDY OF THE USE OF TAPENTADOL}

MT López Mancha, R Sánchez del Moral, MB Contreras Rey, E Rodríguez Molins, J Estaire Gutiérrez, MM Romero Alonso. Infanta Elena Hospital, Pharmacy, Huelva, Spain

\subsection{6/ejhpharm-2019-eahpconf.316}

Background Tapentadol is a potent analgesic with opioid agonist properties of the $\mu$ receptor and additional properties of inhibition of norepinephrine recapture. It is indicated to control chronic intense pain in adults, which can only be treated adequately with an opioid analgesic.

Purpose To analyse and evaluate the use of tapentadol in a second-level hospital and describe the characteristics of patients who have been treated.

Material and methods Observational, descriptive study. All episodes of treatment with tapentadol in the hospital since 1 January 2017 (date of its introduction in the pharmacotherapeutic guide) until 1 October 2018 were included. Patient variables (sex, age, dose, indication and service in which they were admitted) were retrieved from the electronic medical records (Diraya) and all data related to tapentadol posologies (dosage and frequency) were reviewed through the prescriptions of patients using Silicon, the electronic prescribing system. All data obtained were included in a database designed for this study.

Results During the period of our study 50 patients were treated, 44\% males with an average age of 66.9 (44-86) years and 56\% females whose average age was 66.7 (29-87) years. The most prescribed dose was $50 \mathrm{mg} / 12$ hours (60\%), followed by $100 \mathrm{mg} / 12$ hours (28\%), $200 \mathrm{mg} / 12$ hours (6\%), $150 \mathrm{mg} / 12$ hours (4\%) and finally $25 \mathrm{mg} / 12$ hours (2\%).
Regarding the prescription of tapentadol in terms of pathologies, it was emphasised that $52 \%$ of patients suffered herniated discs and/or vertebral fractures, 30\% chronic pain, generalised polyarthritis and fibromyalgia, $10 \%$ cancer pain, $6 \%$ chronic tension headaches and/or migraines, while only 2\% suffered from advanced Parkinson's disease.

The medical services that made these prescriptions were: $44 \%$ internal medicine, $38 \%$ orthopaedic surgery and traumatology, 12\% neurology, 4\% urology and 2\% palliative care.

Conclusion The use of tapentadol is more frequent in females than in males. Respecting ages, they are very similar in both sexes.

The highest doses belong to patients with oncological pain.

The prescription of tapentadol was mainly for non-oncological pain $(90 \%)$ and, within it, the pathologies mainly treated were spinal injuries (herniated discs and/or vertebral fractures).

Orthopaedic surgery, traumatology and internal medicine were the main prescribers.

\section{REFERENCES AND/OR ACKNOWLEDGEMENTS}

No conflict of interest.

\section{CPS-168 POSTOPERATIVE PAIN MANAGEMENT AND PAIN REFERRED BY ADULT PATIENTS 24 HOURS AFTER SURGERY AND ONE MONTH AFTER DISCHARGE}

P Martinez Ortega* A Gimenez-Manzorro, A Ribed-Sanchez, A de Lorenzo-Pinto, E GarciaMartin, S Garcia-Sanchez, MA Amor-Garcia, FJ Garcia-Moreno, A Melgarejo-Ortuño, A Herranz-Alonso, M Sanjurjo-Saez. Hospital General Universitario Gregorio Marañon, Pharmacy Department, Madrid, Spain

\subsection{6/ejhpharm-2019-eahpconf.317}

Background Inappropriate pain management during the surgical process could lead to worse surgery outcomes and quality of life. Hospital pharmacists should develop strategies to improve pain management.

Purpose To describe postoperative pain treatment, the proportion of patients who referred moderate-severe pain 24 hours after surgery and 1 month after discharge, and number of visits to the primary care physician, the emergency room (ER) or re-admissions related to postoperative pain during the first month after surgery.

Material and methods An observational, descriptive, prospective study was conducted from February to September 2018. Inclusion criteria: adult patients admitted to surgery departments 24 hours after surgery. Collected variables: demographic, pharmacotherapeutic and clinical. The intensity of the pain was measured by the numerical verbal scale (NVS). The frequency of patients with moderate-severe pain (NVS $\geq 4$ ) was calculated at 24 hours after intervention and 30 days after discharge.

Results

- One-hundred and thirty-three patients (59\% males) were recruited (median age 62.7 years, interquartile range 52.072.3).

- One-hundred and seventeen patients (88.0\%, CI 95\%: $82.4 \%$ to $93.5 \%$ ) were prescribed an analgesic around-theclock.

- Ninety-eight patients (73.7\%, CI 95\%: $66.2 \%$ to $81.2 \%$ ) were prescribed acetaminophen, dipyrone or a NSAID around-the-clock. Thirty-eight of them $(38.8 \%$, CI 95\%:29.1\% to $48.4 \%$ ) were prescribed a potent opioid as a rescue, whereas 28 of them (28.6\%, CI 95\%: $19.6 \%$ to 